\title{
Chapter 9 \\ Development of Risk Assessment Methodology Against External Hazards for Sodium-Cooled Fast Reactors
}

\author{
Hidemasa Yamano, Hiroyuki Nishino, Yasushi Okano, \\ Takahiro Yamamoto, and Takashi Takata
}

\begin{abstract}
In this study, hazard evaluation methodologies were developed for the decay heat removal of a typical sodium-cooled fast reactor in Japan against snow, tornado, wind, volcanic eruption, and forest fire. In addition, probabilistic risk assessment and margin assessment methodologies against snow were developed as well. Snow hazard curves were developed based on the Gumbel and Weibull distributions using historical records of the annual maximum values of snow depth and daily snowfall depth. Wind hazard curves were also evaluated using the maximum wind speed and instantaneous speed. The tornado hazard was evaluated by an excess probability for the wind speed based on the Weibull distribution multiplied by an annual probability of the tornado strike at a target plant. The volcanic eruption hazard was evaluated using geological data and tephra diffusion simulation which indicated tephra layer thickness and tephra diameter. The forest fire hazard was evaluated based on numerical simulation which contributed to creating a response surface of frontal fire intensity and Monte Carlo simulation for excess probability calculation. After developing an event tree and failure probabilities, the snow PRA showed the order of $10^{-7} /$ year of core damage frequency. Event sequence assessment methodology was also developed based on plant dynamics analysis coupled with continuous Markov chain Monte Carlo method in order to apply to the event sequence against snow. Furthermore, this study developed the snow margin assessment methodology that the margin was regarded as the snowfall duration to the decay heat removal failure which was defined as when the snow removal speed was smaller than the snowfall speed.
\end{abstract}

H. Yamano $(\bowtie) \bullet H$. Nishino $\bullet$ Y. Okano

Japan Atomic Energy Agency, 4002 Narita-cho, Oarai, Ibaraki 311-1393, Japan

e-mail: yamano.hidemasa@jaea.go.jp

T. Yamamoto

Geological Survey of Japan, AIST, 1-1-1 Higashi, Tsukuba, Ibaraki 305-8567, Japan

T. Takata

Osaka University, 2-1 Yamada-oka, Suita, Osaka 565-0871, Japan

(C) The Author(s) 2016

K. Kamae (ed.), Earthquakes, Tsunamis and Nuclear Risks,

DOI 10.1007/978-4-431-55822-4_9 
Keywords Probabilistic risk assessment - Sodium-cooled fast reactor • External hazard $\bullet$ Snow $\bullet$ Tornado $\bullet$ Wind $\bullet$ Rain $\bullet$ Volcanic eruption $\bullet$ Forest fire

\subsection{Introduction}

External hazard risk is increasingly being recognized as important for nuclear power plant safety after the Fukushima Daiichi nuclear power station accident. To improve nuclear plant safety, risk assessment methodologies against various external hazards are necessary, although a probabilistic risk assessment (PRA) methodology against an earthquake has been developed as a priority because of the importance of consequence of an earthquake. The Atomic Energy Society of Japan published a seismic PRA standard in 2007 [1] and a tsunami PRA standard in 2012 [2] which was vigorously developed as an important issue after the Fukushima Daiichi accident caused by a tsunami. Except for the two external hazards, there are no PRA standards against various external hazards in Japan. An alternative methodology different from the PRA was developed in Europe for complementary safety assessments, so-called stress tests [3]. This methodology was useful to show a margin to core damage against earthquake and flood. Since the most challenge in developing external PRA methodologies is to quantify the intensity of the external hazards for the assessment, the stress test methodology would be useful and effective to suggest safety measures and accident managements that can extend margins to core damage against external hazards.

This study aims mainly at a contribution to the risk assessment and safety improvement of the decay heat removal function of a prototype sodium-cooled fast reactor (SFR) in Japan. It is well known that an earthquake is the most important external hazard that would have a potential structural impact on system, structure, and components of plants. In typical light water reactors (LWRs), flooding including tsunami is an important hazard because its heat sink is sea (river), which is also well known after the Fukushima Daiichi nuclear power station accident. On the other hand, the external flooding is not so significant in SFRs of which heat sink is air. The decay heat removal system (DHRS) of the SFR utilizes air coolers (ACs) located at high elevation, which might be affected by aboveground hazards. This study also takes into account effects on ventilation and air-conditioning system, emergency power supply system, and so on, for which air is usually taken.

This study addresses extreme weathers (snow, tornado, wind, and rainfall), volcanic phenomena, and forest fire as representative aboveground external hazards, which was selected through a screening process [4]. In the first screening, after all foreseeable external hazards were exhaustively identified, a wide variety of external hazards were screened out in terms of site conditions, impact on plant, progression speed, envelop, and frequency. In the second screening, the external hazards were selected on a basis of the scope of this study (aboveground natural hazards). Similar hazards were also merged; e.g., hail can be enveloped by tornado- 
induced missiles. Combination of external hazards is very important in the risk assessment. For instance, in terms of aboveground hazards, this study would address the following hazards: strong wind and heavy rain, snow and cold temperature, volcanic eruption and rain, and so on.

When an extreme external hazard occurs, the nuclear plant is expected to be shut down normally. Therefore, only the decay heat removal function was taken into account, assuming success of reactor shutdown in this study. Although the Fukushima Daiichi accident lessons suggested the importance of a spent fuel pool, this study focuses as a first step on event sequences resulting in reactor core damage because a grace period of accident management is short under hot condition in a full-power operation. The developed methodology is applied mainly to SFRs, though it would also be basically applicable for LWRs in which air is necessary for emergency diesel generators.

The objective of this study is to develop both the margin assessment and PRA methodologies against the representative external hazards. The overview of this study is schematically illustrated in Fig. 9.1. The PRA would indicate a core damage frequency (CDF), which calculates a summation of conditional heat removal failure probabilities multiplied by hazard occurrence frequencies which is based on a hazard curve representing relation between the frequency and the hazard intensity. The margin assessment would show the extension of margins from a design basis to the core damage by introducing several measures including accident management. An advantage of the margin assessment methodology is un-necessity of quantitative external hazard evaluation. Since the event sequence evaluation is needed both for the margin assessment and PRA, a difference between them is quantification of external hazards.

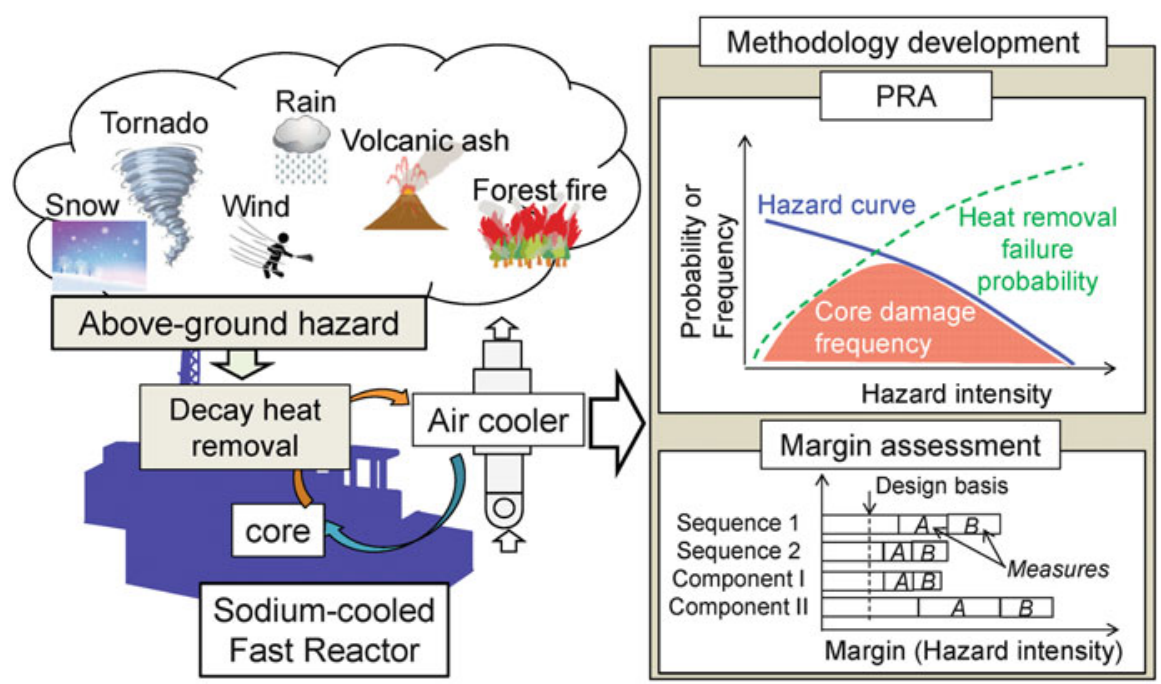

Fig. 9.1 Overview of methodology development 
The present paper is intended to develop hazard evaluation methodologies against snow, tornado, wind, volcanic eruption, and forest fire. This paper also describes the PRA and margin assessment methodologies against snow.

\subsection{External Hazard Evaluation Methodologies}

\subsubsection{Snow}

The snow hazard indexes are the annual maximum snow depth and the annual maximum daily snowfall depth. Snow hazard curves for the two indexes were developed using 50-year historical weather records at the prototype SFR site which is located in Japan Sea side central area [4].

In this study, a snow hazard evaluation methodology was developed according to the following procedure. At first, the annual maximum data of the snow depth and daily snowfall depth were collected. Using these data, the annual excess probability was evaluated by plotting position formula Weibull, Hazen, and Cunnane for general use. Of the three formulas, it is said that the Cunnane is the best suitable and applicable to all probability distributions. Next, the parameters of Gumbel or Weibull cumulative probability distributions were determined by a least square method. Using the annual excess probability, the snow hazard curves were successfully obtained after checking the conformance and stability evaluations in terms of the annual maximum snow depth and the annual maximum daily snowfall depth. Figure 9.2 shows the snow hazard curves using the Gumbel and Weibull distributions. It should be noted that the difference between the two distributions becomes large in a low-frequency range exceeding the measured data $\left(\sim 10^{-2} /\right.$ year $)$. This may be caused by epistemic uncertainty (i.e., lack of knowledge). Considering this uncertainty, conservative evaluations or sensitivity analysis is useful and recommended in the risk assessment.

Fig. 9.2 Snow hazard curve

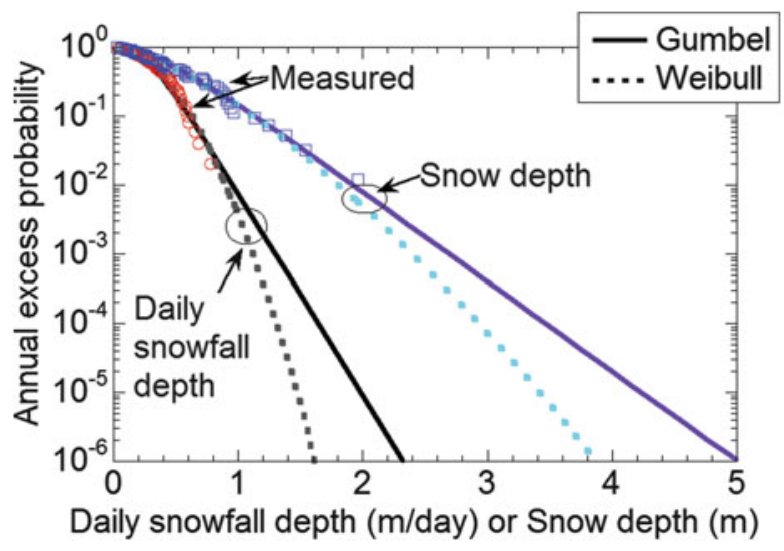




\subsubsection{Tornado}

Wind scales estimated based on structural damage caused by a tornado are usually represented by Fujita scale, which is defined as F0 $=17-32 \mathrm{~m} / \mathrm{s}$ (average time: $\sim 15 \mathrm{~s}), \mathrm{F} 1=33-49 \mathrm{~m} / \mathrm{s}(\sim 10 \mathrm{~s}), \mathrm{F} 2=50-69 \mathrm{~m} / \mathrm{s}(\sim 7 \mathrm{~s}), \mathrm{F} 3=70-92 \mathrm{~m} / \mathrm{s}(\sim 5 \mathrm{~s})$, $\mathrm{F} 4=93-116 \mathrm{~m} / \mathrm{s}(\sim 4 \mathrm{~s})$, and F5 $=117-142 \mathrm{~m} / \mathrm{s}(\sim 3 \mathrm{~s})$.

The procedure of estimation for the tornado hazard curve is as follows. The first step is to select an area for estimating a tornado hazard curve in Japan and to analyze historical tornado data recorded in the selected area. This study selects one of the areas along the seashore of Japan Sea including Hokkaido, which includes the SFR site. The range to collect tornado data is $5 \mathrm{~km}$ inland and sea from the seashore in this area. The second step is to estimate the annual probability of the tornado strike at the target nuclear plant. The third step is to estimate the excess probability for maximal wind speed calculated from Weibull distribution. The final step is to multiply the annual probability estimated in the second step by the excess probability estimated in the third step. By this calculation, the tornado hazard curve was successfully estimated [5].

\subsubsection{Strong Wind}

The wind hazard index is the annual maximum instantaneous wind speed which is used to estimate missile speed [6]. Likewise the snow hazard curve, a basic concept of this methodology is a generalized estimation way, which is characterized by obtaining appropriate probability distribution through the conformance and stability evaluations.

After the collection of wind speed data, an annual excess probability distribution can be evaluated by using wind data based on plotting position formula. The strong wind hazard curves were developed using the Gumbel and Weibull distributions, of which parameters were calculated by a least square method. Figure 9.3 shows the hazard curves based on the Gumbel and Weibull distributions. In the Gumbel distribution, the estimated curve decreases linearly less than 0.1 of the annual excess probability. In the Weibull distribution, on the other hand, the curve decreases like a quadratic curve. From this figure, the larger the difference between the two estimated distributions is, the lower the excess probability is.

\subsubsection{Volcanic Eruption}

Volcanic ash was identified as the key phenomena of the volcanic eruption hazard in the vicinity of the plant site, so that the volcanic ash hazard evaluation methodology is being developed using geological data and numerical simulations of ash diffusion. Geological data survey indicated about $2 \times 10^{-4} /$ year of volcanic ash 
Fig. 9.3 Wind hazard curve

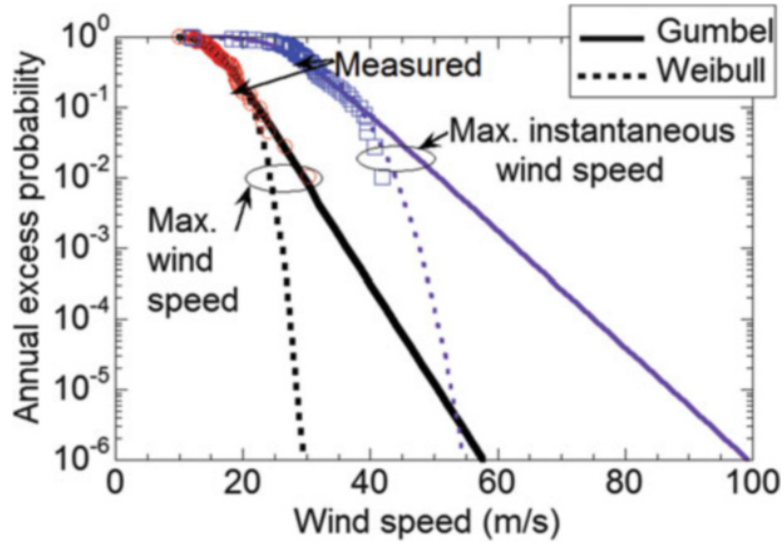

Fig. 9.4 Calculated tephra layer thickness and tephra diameter

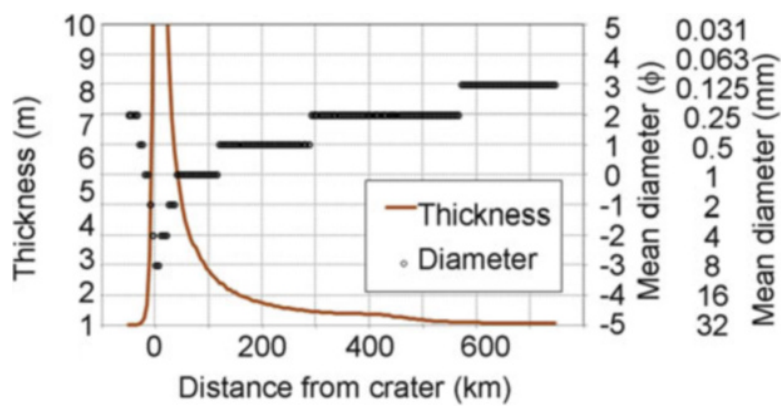

fallout around the site, which was based on boring data of 22 ash fallouts since 110,000 years ago. This includes thin ash layers. For thicker ash layers than $5 \mathrm{~cm}$, the volcanic ash fallout frequency was estimated about $2 \times 10^{-5} /$ year.

From the geological data, the maximum thickness of the ash fallouts around the plant site is about $50 \mathrm{~cm}$ of the Daisen-Kurayoshi tephra that erupted about 50,000 years ago. This study carried out numerical simulation of the Daisen-Kurayoshi tephra diffusion using the Tephra2 code [7]. The simulation showed well-reproduced ash fallout distribution in a wide area. Figure 9.4 shows calculated fallout thickness and tephra diameter along the distance from the crater. A discharge rate of fallout was estimated about $10^{19} \mathrm{~kg} / \mathrm{s}$, and eruption duration was 4-8 $\times 10^{4} \mathrm{~s}$ [8].

One of crucial issues of volcanic eruption is to investigate characterization of volcanic particle, in particular fine volcanic ash less than $0.06 \mathrm{~mm}$ in diameter, which could disperse vast area from the source volcano and be easily remobilized by surface wind and precipitation after the deposition. In order to quantify quantitative characteristics of fine volcanic ash particle, we sampled volcanic ash directly falling from the eruption plume from Sakurajima volcano before landing on ground. A newly introduced high precision digital microscope and particle grain size analyzer allowed us to develop hazard evaluation method of fine volcanic ash particle [9]. 


\subsubsection{Forest Fire}

The phenomena of a forest fire that would give potential impacts on nuclear plants are identified as fire, flame, smoke, and flying objects. To evaluate their impacts, numerical simulations are utilized by using the FARSITE code with appropriate numerical conditions: fire breakout, fire spread condition including extinguishing, weather data, vegetation data, and simulation conditions. For these conditions, branch probabilities are provided based on a logic tree. The simulation showed that the wind speed and relative humidity were sensitive to the forest fire hazard [10].

A preliminary hazard evaluation was carried out using a response surface of frontal fire intensity with regard to the wind speed and relative humidity. The evaluated hazard curve is such that the annual excess probability is about $1.0 \times 10^{-4} /$ year for the frontal fireline intensity of $200 \mathrm{~kW} / \mathrm{m}$ and about $1.3 \times 10^{-5} /$ year for $300 \mathrm{~kW} / \mathrm{m}[11]$.

Smoke is also important in the forest fire hazard evaluation. The ALOFT-FT code was applied to the smoke transport analysis in order to investigate potential impact on air filters for the DHRS. The total amount of particle matters estimated was estimated well below the operational limit of the air filter [12].

\subsection{Risk Assessment Methodologies Against Snow}

\subsubsection{PRA}

Snow hazard categories were obtained from a combination of the daily snowfall depth (snowfall speed) and snowfall duration that can be calculated by dividing the snow depth by the snowfall speed [13]. For each snow hazard category, accident sequences were evaluated by producing event trees that consist of several headings representing the loss of the decay heat removal. Air ventilation channels must be ensured for the important components in this PRA: emergency diesel generator, ACs in the decay heat removal system. The natural circulation decay heat removal is expected in the SFR, so that manual operation of the AC dampers is required in a total blackout situation (the loss of direct current-powered equipment). Snow removal operation was introduced into the event trees as the accident managements. To succeed in the snow removal, plant personnel have to be able to reach the door to open on the building roof and then have to remove accumulated snow from the door to the air inlets. The failure probabilities were evaluated as a function of hazard intensity.

The decay heat removal failure probability of each event sequence was obtained by introducing the failure probability into the event tree. The CDF by the snow hazard category can be calculated by multiplying each heat removal failure probability and each snow hazard occurrence frequency. In total, the CDF brings the 


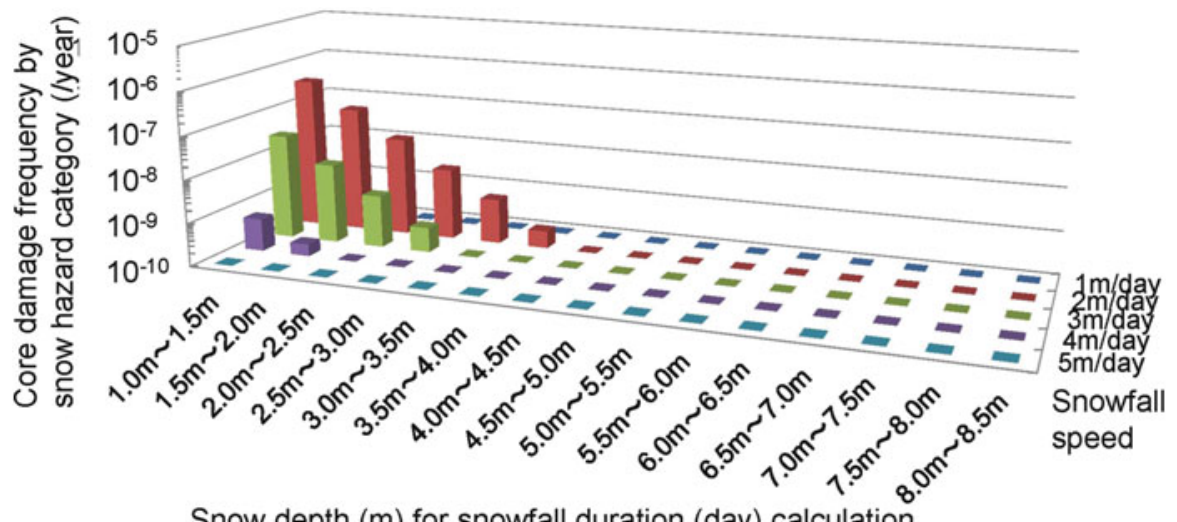

Snow depth $(m)$ for snowfall duration (day) calculation

Fig. 9.5 Core damage frequency by snow hazard category

order of $10^{-7} /$ year. Figure 9.5 shows the CDF by the snow hazard category, in which the dominant snow hazard category was a combination of 1-2 m/day of snowfall speed and $0.5-0.75$ day of snowfall duration (1-1.5 $\mathrm{m}$ of snow depth). The dominant sequence was that the personnel failed the door opening on the roof after the 1st awareness of the snow removal necessity, resulting in the loss of decay heat removal system due to snow. Importance and sensitivity analyses indicated a high risk contribution to secure the access routes.

Looking at Fig. 9.2, the dominant snowfall speed of 1-2 m/day is approximately $10^{-2} /$ year of annual access probability (at $1 \mathrm{~m} /$ day of snowfall), and the dominant snow depth of $1-1.5 \mathrm{~m}$ is approximately $10^{-1} /$ year (at $1 \mathrm{~m}$ of snow depth). Such frequencies are not so low that we are aware of the importance of relatively high frequent hazard through this study. The PRA results would be served for the development of safety measures and accident management. In general, although careful attention may be often paid to extremely low-frequency events bringing high consequence, significant hazard intensity could be clarified through PRA studies.

The event tree methodology is well known as a classical manner for the PRA; however, it is difficult to express time-dependent event sequences including recovery. Therefore, a new assessment technique was also being developed for the event sequence evaluation based on a continuous Markov chain Monte Carlo method with plant dynamics analysis [14].

\subsubsection{Margin Assessment}

We introduced an effective snow removal speed which is defined as a daily snow removal speed multiplied by a performance factor of the snow removal work so that plant personnel can remove accumulated snow in a certain time. If this effective 
Fig. 9.6 Margin assessment against snow

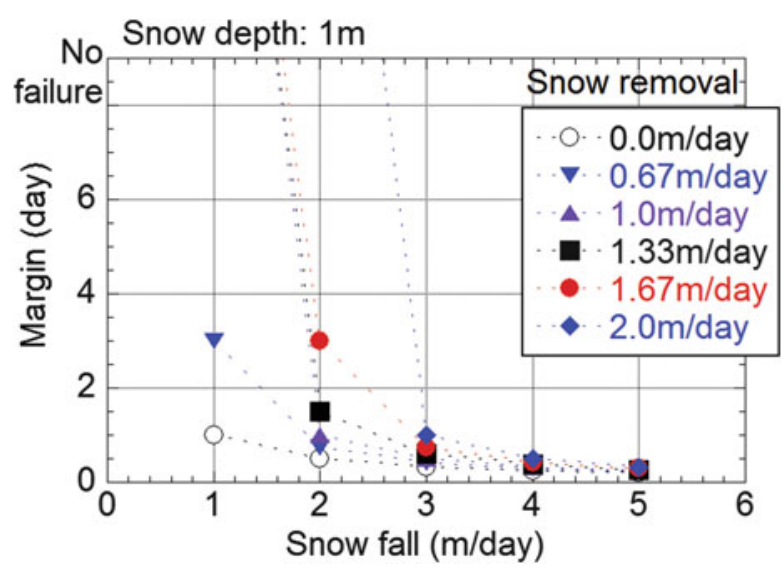

snow removal speed exceeds the snowfall speed, the scenario leads to no heat removal failure. On the other hand, if the effective snow removal speed falls below the snowfall speed, the heat removal failure scenario appears as a result of gradual continuous accumulation of snow. The margin (day) can be defined as the snowfall duration until when the accumulated snow depth reaches the snow depth corresponding to the heat removal failure. In this definition, the accumulated snow depth can be calculated as a difference between the snowfall speed and the effective snow removal speed.

This study assumed the failure to secure the access routes when the snow depth reached $1 \mathrm{~m}$ as well as conservatively assumed $1 \mathrm{~m}$ for the snow depth corresponding to the heat removal failure in the decay heat removal system. The performance factor of the snow removal work was set $1 / 3$, assuming totally $8 \mathrm{~h}$ per day for plant personnel to remove the snow. These assumptions were applied to the margin assessment. The margin assessment result is presented in Fig. 9.6, in which the parameter is the effective snow removal speed. No heat removal failure appears if the snow removal speed is higher than $3 \mathrm{~m} /$ day $(1 \mathrm{~m}$ /day of effective snow removal speed) when the snowfall speed is $1 \mathrm{~m}$ /day. Even if the same snow removal speed is applied, the heat removal failure scenario appears to indicate 1 day of margin when the snowfall speed is $2 \mathrm{~m}$ /day. Considering such a situation, it is important to flexibly strengthen a snow removal action plan such as an increase in the performance factor of the snow removal work.

\subsection{Conclusion}

In this study, hazard evaluation methodologies were developed for the decay heat removal function of a typical sodium-cooled fast reactor in Japan against snow, tornado, wind, volcanic eruption, and forest fire. In addition, PRA and margin 
assessment methodologies against snow were developed as well. Snow hazard curves were developed based on the Gumbel and Weibull distributions using historical records of the annual maximum values of snow depth and daily snowfall depth. Likewise this snow hazard evaluation, wind hazard curves were also developed using the maximum wind speed and instantaneous speed. The tornado hazard data were used based on the Fujita scale in a wide area along the seashore of Japan Sea. Using the historical records, the tornado hazard curve was estimated as an excess probability for the wind speed based on the Weibull distribution multiplied by an annual probability of the tornado strike at the target nuclear plant. The volcanic eruption hazard was evaluated using geological data and tephra diffusion simulation which indicated tephra layer thickness and tephra diameter. The forest fire hazard was evaluated based on numerical simulation which contributed to creating a response surface of frontal fire intensity with regard to the wind speed and relative humidity, etc., and Monte Carlo simulation for excess probability calculation. For the snow PRA, the accident sequence was evaluated by producing event trees which consist of several headings representing the loss of decay heat removal. Snow removal action and manual operation of the air cooler dampers were introduced into the event tree as accident managements. In this paper, the snow PRA showed the order of $10^{-7} /$ year of core damage frequency. The dominant snow hazard category was the combination of 1-2 $\mathrm{m} /$ day of snowfall speed and $0.5-0.75$ day of snowfall duration. Event sequence assessment methodology was also developed based on plant dynamics analysis coupled with continuous Markov chain Monte Carlo method in order to apply to the event sequence against snow. For the snow margin assessment, the index is the combination of a snowfall speed and duration. Since snow removal can be expected for the snowfall, this study developed the snow margin assessment methodology that the margin was regarded as the snowfall duration until when the accumulated snow depth reaches the snow depth corresponding to the decay heat removal failure.

Acknowledgments The present study is the result of "Research and Development of Margin Assessment Methodology of Decay Heat Removal Function against External Hazards" entrusted to Japan Atomic Energy Agency by the Ministry of Education, Sports, Science and Technology (MEXT) in Japan.

Open Access This chapter is distributed under the terms of the Creative Commons Attribution Noncommercial License, which permits any noncommercial use, distribution, and reproduction in any medium, provided the original author(s) and source are credited.

\section{References}

1. Atomic Energy Society of Japan (AESJ) (2007) Implementation standard of seismic probabilistic safety assessment for nuclear power plants: 2007. AESJ-SC-P006:2007

2. Atomic Energy Society of Japan (AESJ) (2011) Implementation standard concerning the tsunami probabilistic risk assessment of nuclear power plants: 2011. AESJ-SC-RK004E:2011 
3. European Nuclear Safety Regulators Group (ENSREG) (2012) Peer review report; stress tests performed on European nuclear power plants. 25 Feb 2012 (online)

4. Yamano H, Nishino H, Kurisaka K, Sakai T, Yamamoto T, Ishizuka Y, Geshi N, Furukawa R, Nanayama F, Takata T (2014) Development of margin assessment methodology of decay heat removal function against external hazards - project overview and preliminary risk assessment against snow. In: Proceedings of the 12th probabilistic safety assessment and management conference (PSAM 12), Honolulu, Hawaii, USA, 22-27 June 2014, No. 44

5. Nishino H, Kurisaka K, Yamano H (2014) Development of margin assessment methodology of decay heat removal function against external hazards (2) Tornado PRA methodology. In: Proceedings of the 10th international topical meeting on nuclear thermal-hydraulics, operation and safety (NUTHOS-10), Okinawa, Japan, 14-18 Dec 2014, NUTHOS10-1068

6. Yamano H, Nishino H, Kurisaka K, Okano Y, Sakai T, Yamamoto T, Ishizuka Y, Geshi N, Furukawa R, Nanayama F, Takata T, Azuma E (2015) Development of risk assessment methodology against external hazards for sodium-cooled fast reactors: project overview and strong wind PRA methodology. In: Proceedings of the international congress on advances in nuclear power plants (ICAPP2015), Nice, France, 3-6 May 2015, No. 15031

7. Connor CB, Hill BE, Winfrey B, Franklin NM, Lafemina PC (2001) Estimation of volcanic hazards from tephra fallout. Nat Hazards Rev 2:33-42

8. Yamamoto T, Sugiyama M, Tajima Y (2014) Simulation of the Daisen-Kurayoshi Tephra, in the San-in District, SW Japan, using Tephra2. Japan Geoscience Union Meeting 2014, 28 Apr2 May 2014, SVC52-01

9. Nanayama F, Furukawa R, Ishizuka Y, Yamamoto T, Geshi N, Oishi M (2013) Characterization of fine volcanic ash from explosive eruption from Sakurajima Volcano, South Japan. Transaction of American Geophysical Union 2013 Fall Meeting, San Francisco, CA, USA, 9-13 Dec 2013

10. Okano Y, Yamano H (2014) Development of margin assessment methodology of decay heat removal function against external hazards (3) Forest fire hazard assessment methodology. In: Proceedings of the 10th international topical meeting on nuclear thermal-hydraulics, operation and safety (NUTHOS-10), Okinawa, Japan, 14-18 Dec 2014, NUTHOS10-1018

11. Okano Y, Yamano H (2015) Development of a hazard curve evaluation method for a forest fire as an external hazard. In: Proceedings of the international topical meeting on probabilistic safety assessment and analysis (PSA 2015), Sun Valley, ID, USA, 26-30 Apr 2015

12. Okano Y, Yamano H (2015) Development of risk assessment methodology of decay heat removal function against external hazards for sodium-cooled fast reactors (3) Numerical simulations of forest fire spread and smoke transport as an external hazard assessment methodology development. In: Proceedings of the 23rd international conference on nuclear engineering (ICONE-23), Chiba, Japan, 17-21 May 2015, ICONE23-1009

13. Yamano H, Nishino H, Kurisaka K, Okano Y, Sakai T, Yamamoto T, Ishizuka Y, Geshi N, Furukawa R, Nanayama F, Takata T, Azuma E (2014) Development of margin assessment methodology of decay heat removal function against external hazards (1) Project overview snow PRA methodology. In: Proceedings of the 10th international topical meeting on nuclear thermal-hydraulics, operation and safety (NUTHOS-10), Okinawa, Japan, 14-18 Dec 2014, NUTHOS10-1014

14. Takata T, Azuma E (2014) Development of margin assessment methodology of decay heat removal function against external hazards (4) Event sequence assessment based on continuous Markov Chain Monte Carlo method with plant dynamics analysis. In: Proceedings of the 10th international topical meeting on nuclear thermal-hydraulics, operation and safety (NUTHOS10), Okinawa, Japan, 14-18 Dec 2014, NUTHOS10-1291 